Supporting Information

\title{
Map Figures
}

All maps were created in R 3.20 using ggplot2 2.0.0. The predictions were created on a $25 \times 25 \mathrm{~km}$ grid. Predictions were smoothed using inverse distance weighting and the centers of hexagons were taken as the concentrations used as the fill aesthetic of geom_hex. We used the coord_map function in ggplot2 to project maps into a lambert projection. The "state" map from the ggplot2 mapdata function was used to create state polygons.

\section{Geographic Covariates}

Below is a description of the geographic covariates. An overview of geographic covariates is listed in Table S2a. The 2006 land use types are further broken into categories in Table S2b.

Roadway: EPA year 2000 TeleAtlas data was used for calculating roadway variables. In TeleAtlas, roadways are given different classifications by roadway types (A1: highways, A2: arterials, A3: residential). Proximity roadway variables were calculated separately for each roadway type. forhttp://www.maris.state.ms.us/pdf/CFCCcodes.pdf.

Distance to Road and Near Road Determination: Distance roadways was estimated as the perpendicular distance from the nearest roadway to the site location.

Emissions: EPA's National Emission Inventory (NEI) was used to calculate nearby facility emissions data for Criteria Air Pollutants (CAPs) and Hazardous Air Pollutants (HAPs) emissions. This database also contains stack height which we used to define the modeling variables. We calculate the sum tonnage of NOX, SO2, PM2.5, PM10, and CO from short stacks within a $3 \mathrm{~km}$ buffer and from tall stacks between $3 \mathrm{~km}$ and $15 \mathrm{~km}$ or $30 \mathrm{~km}$ buffer from monitoring locations. Tall stacks were defined as having a height of at least 30 meters. Short stacks were defined as less than 30 meters. Pollutants included were $\mathrm{NOx}, \mathrm{SO}_{2}$, $\mathrm{PM}_{2.5}, \mathrm{CO}, \mathrm{PM}_{10}$. We used the third and final version of the $2002 \mathrm{NEI}$ data posted in January 2008

Elevation: For each monitoring location point we calculated an elevation in meters from a USGS National Elevation Dataset (NED). The resolution of the raster was 1 arc second. We additionally calculated elevation at 24 elevation points in concentric circles at two radii (1000 m. and $5000 \mathrm{~m})$.

Normalized Difference Vegetation Index (NDVI) was calculated from year 2006 satellite data as a 16-day composite. The University of Maryland converted -1 to 1 to pixel brightness scale (0-255). For each monitoring location, we averaged pixel centroids within a given distance radius (radii included $250 \mathrm{~m}$, $500 \mathrm{~m}, 1 \mathrm{~km}$, and $5 \mathrm{~km}$ ), averaging over the days. For each buffer size, we calculated multiple variables: 
the 25th, median, and 75th percentile of the entire year's series, the median of the expected 'high vegetation' season, defined as April 1 - September 30, and the median of the expected 'low vegetation' season, defined as the rest of the year.

\section{Cross-validation Groups}

Since the available monitors changed over time, cross-validation groups were chosen separately for each year. For the conventional cross-validation approach, we selected groups randomly across regions such that a group could contain monitors between regions. For the clustered cross-validation approach, we used a k-means algorithm to split the points by space. This approach is an unsupervised learning technique requiring a pre-specified number of clusters based on proximity to the nearest mean (defined spatially), effectively grouping points into Voronoi polygons given by those means. The distance metric we used to define space was conventional Euclidean distance. Under this approach cross-validation groups were contained within regions, with a predetermined number of clusters per region (West Coast: 4 clusters, Mountain West: 4 clusters, East: 12 clusters) (This decision was made to ensure approximate consistency and stability of the group sizes and locations).

Figure S1: Partial Least Squares loadings for the PLS components in 1990 and 2006

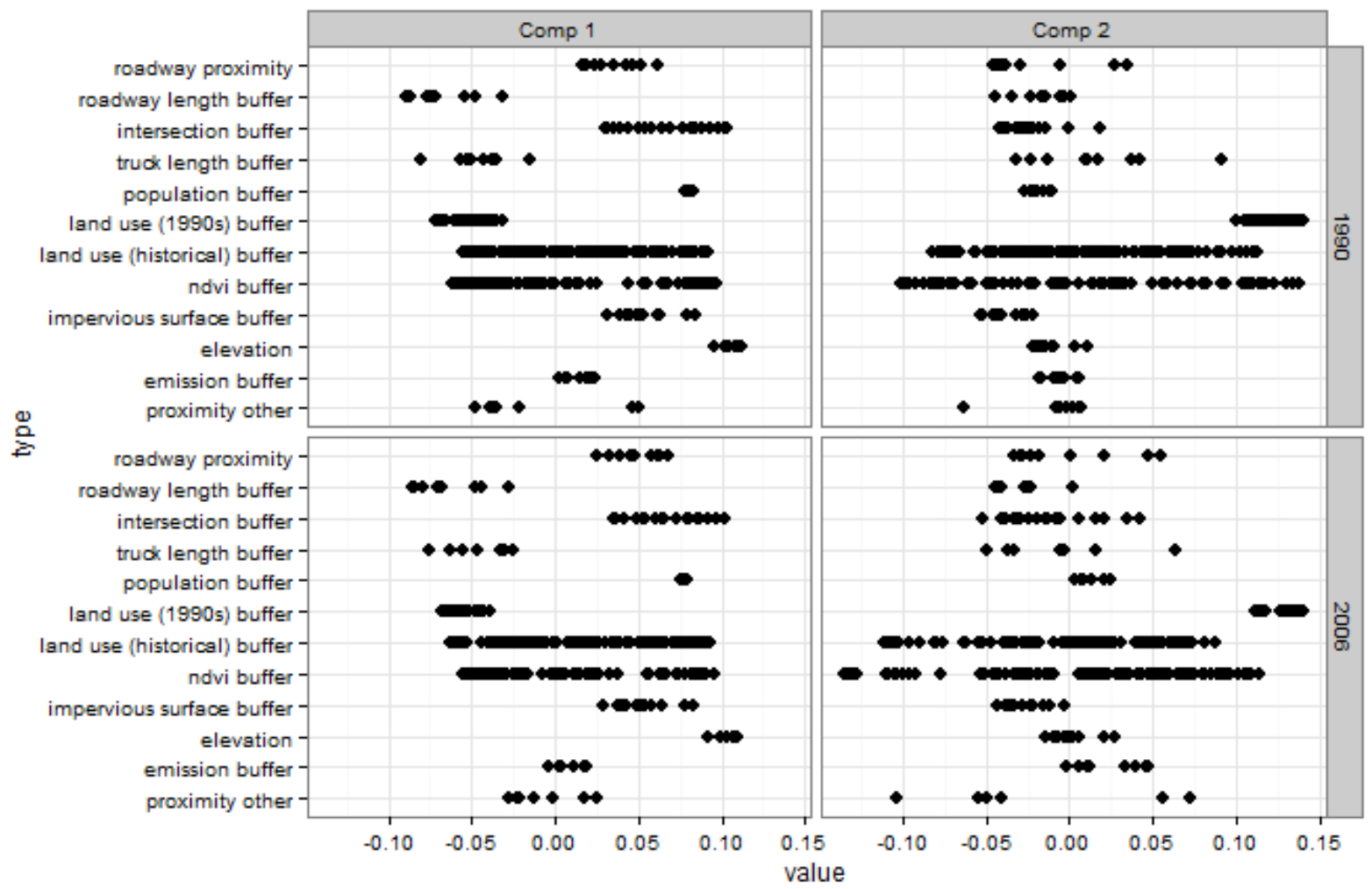


Each point represents a single variable. Variables are grouped into categories (rows) for visualization purposes. A category may contain variables of multiple types (for example, the land use categories include a variety of different land-use classifications). Categories denoted as buffers include repeated versions of each variable calculated for a set of buffer radii (ranging from $50 \mathrm{~m}$ to $10 \mathrm{k}$ depending on the variable). This figure highlight shows one of the two ways in which models vary from year to year with respect to geographic covariates: changes in estimated loadings. Additionally, region-specific regression coefficients for the PLS components vary by year (see Table S4).

Figure 2a: Conventional Cross-validation groups (year 2006)

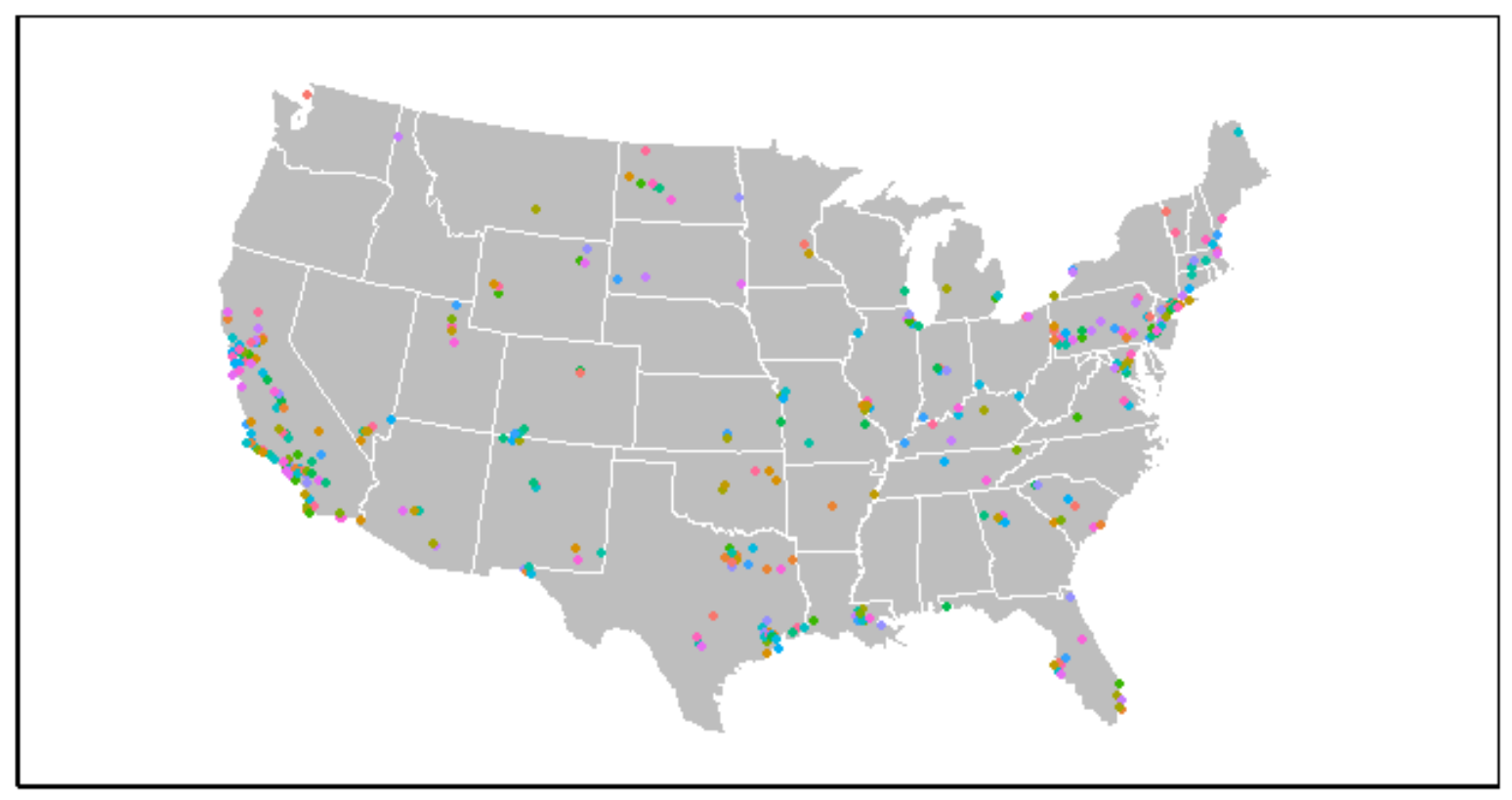

Figure 2b: Conventional Cross-validation groups (year 2006) 


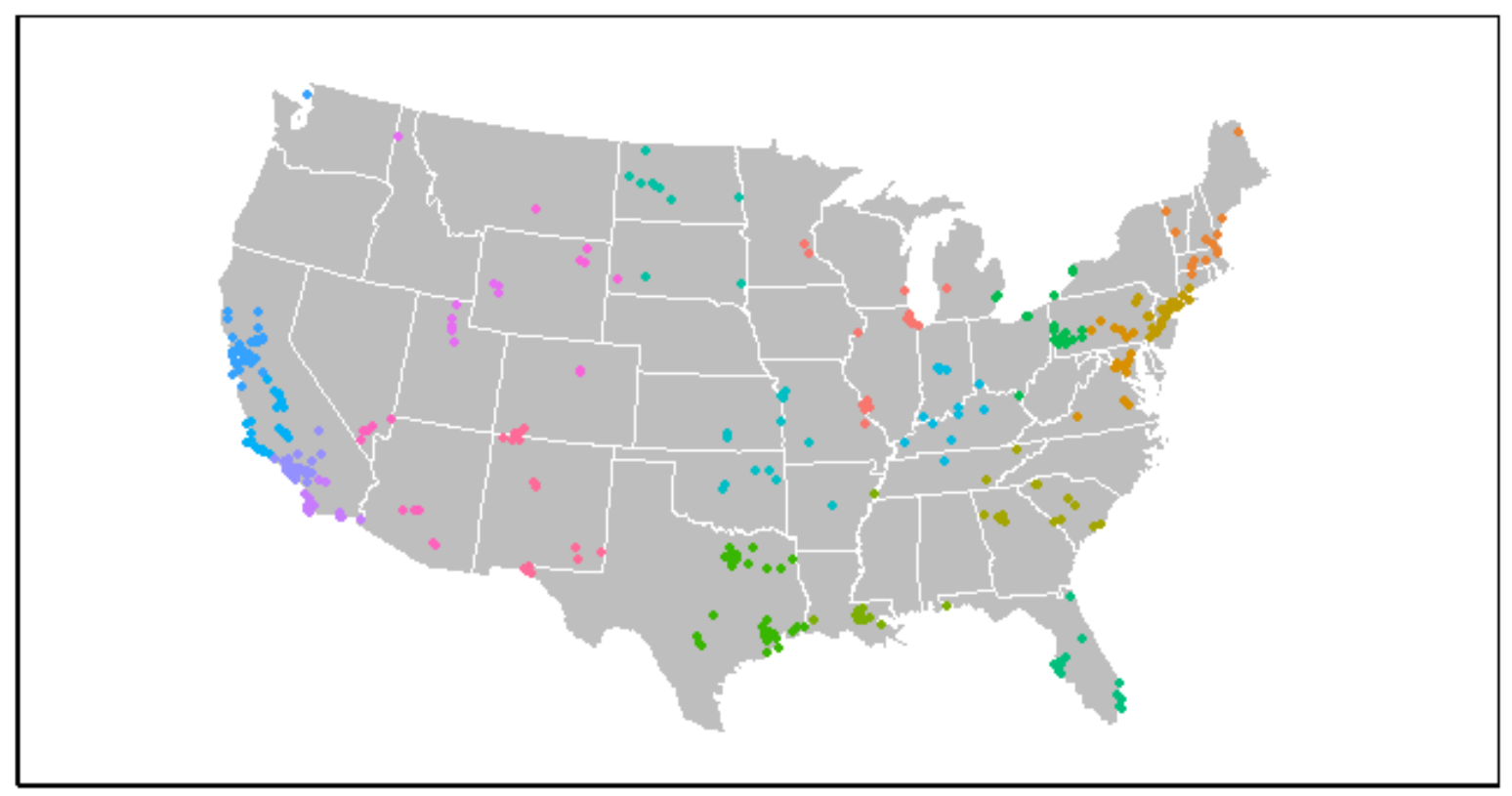

Figure S3a: MEAN Bias by year, estimated using conventional cross-validation

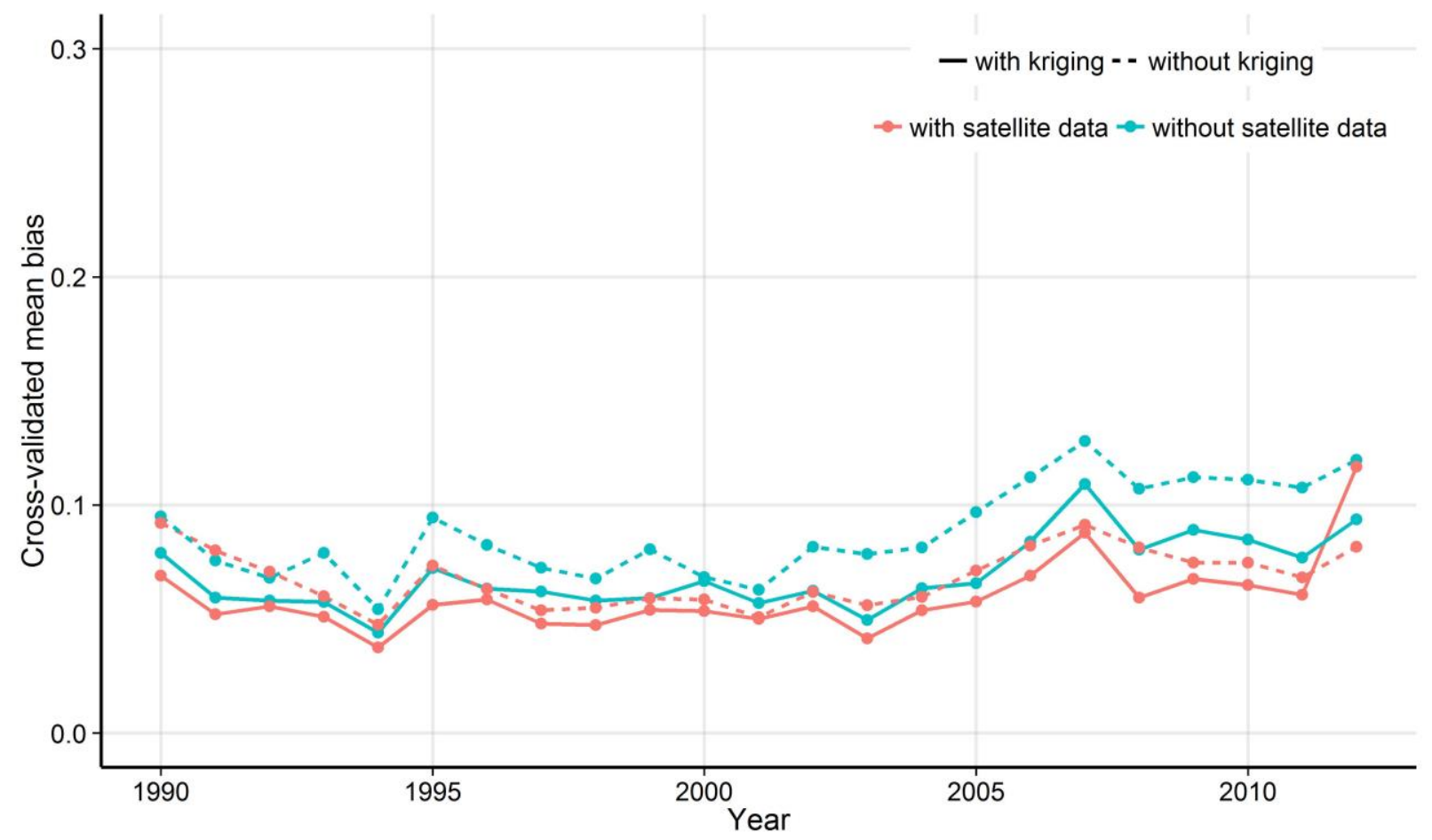

Figure S3b: MEAN Bias by year, estimated using clustered cross-validation 


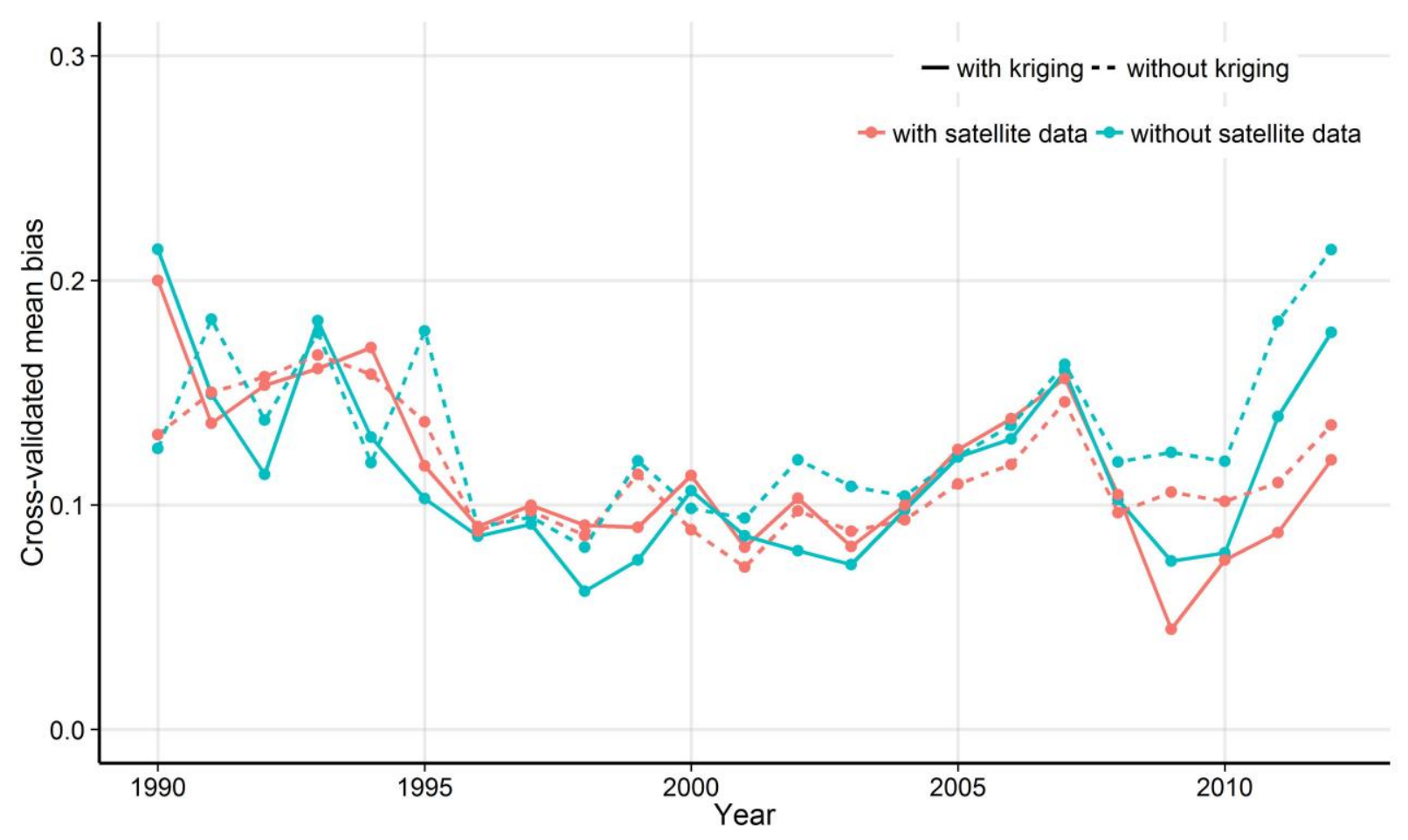

Figure S4: Prediction Errors (Clustered Cross-validation)

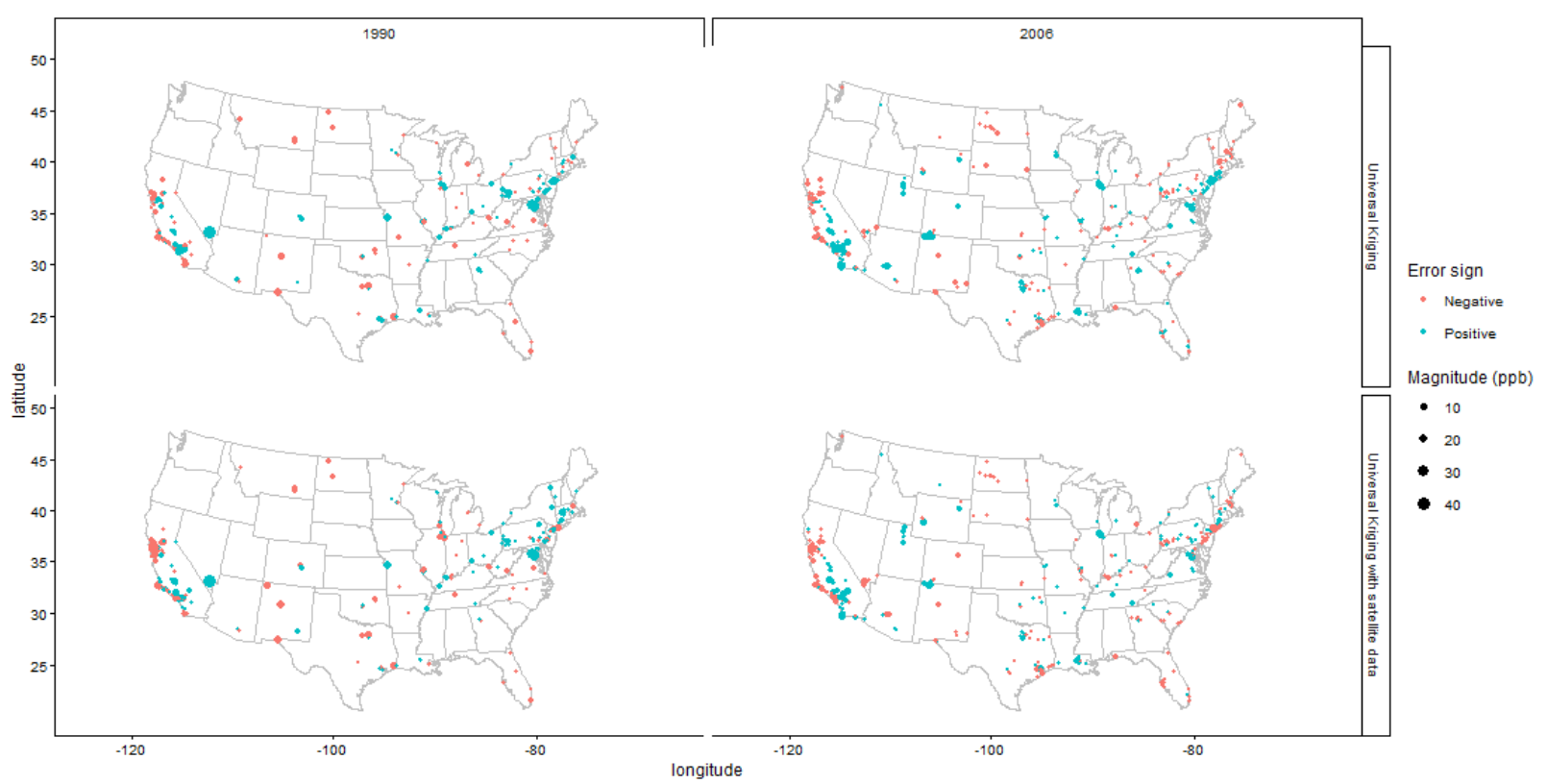

The error of predictions (observed-fitted).

Figure S5: Modeling Approach 


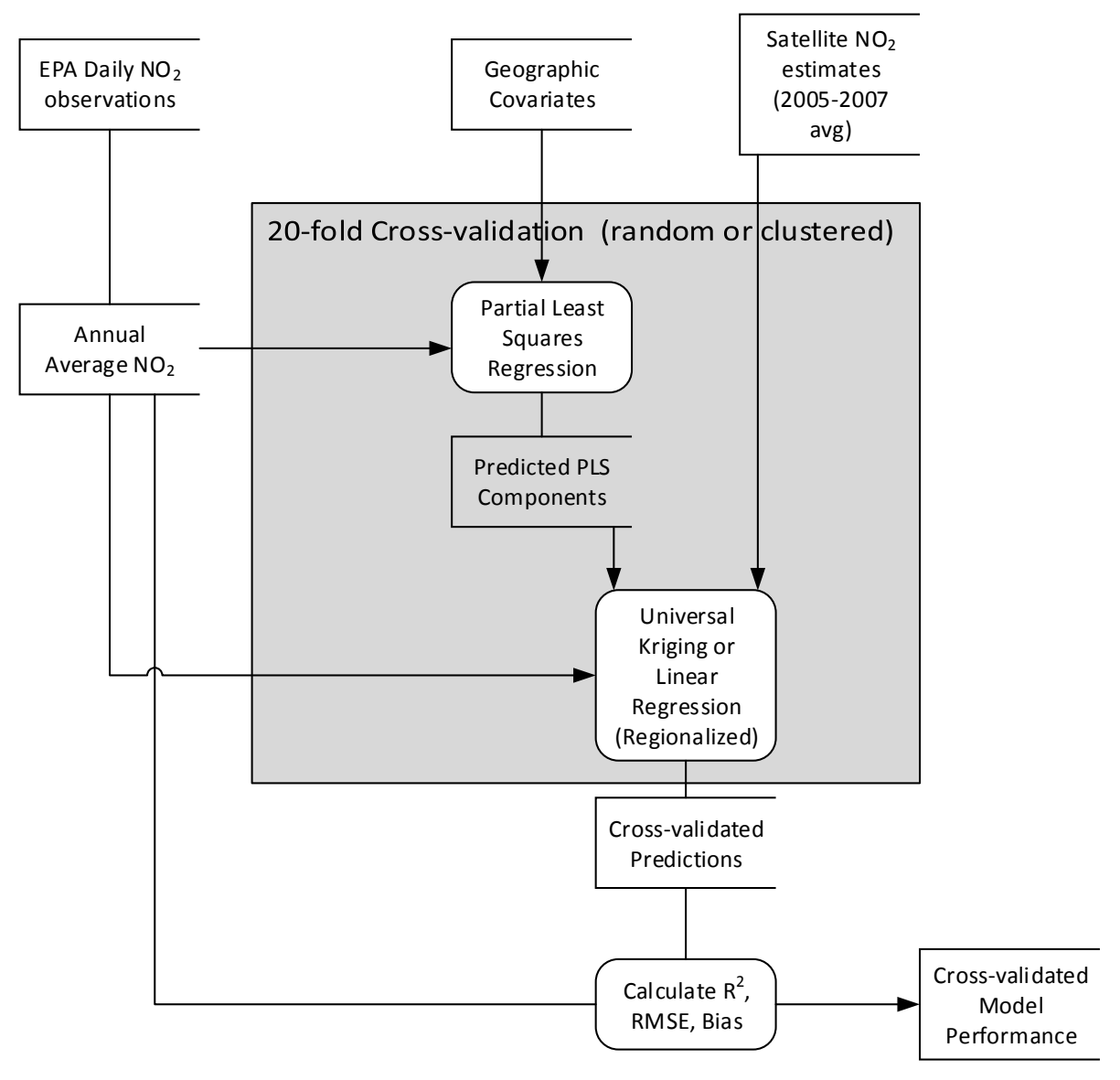

The above process was repeated for each modeling year (1990-2012). Within each year, separate models were fit with and without the satellite estimates and with and without kriging (a total of four model types per year). Each model was assessed separately using random cross-validation and clustered cross-validation.

Table S1: Number of $\mathrm{NO}_{2}$ monitors per year by modeling region

\begin{tabular}{rrrr} 
Year & West Coast & West & \multicolumn{2}{l}{ East } \\
1990 & 89 & 21 & 161 \\
1991 & 94 & 24 & 169 \\
1992 & 100 & 26 & 167 \\
1993 & 94 & 28 & 176 \\
1994 & 112 & 26 & 183 \\
1995 & 119 & 26 & 191 \\
1996 & 103 & 30 & 193 \\
1997 & 109 & 31 & 195 \\
1998 & 104 & 39 & 191 \\
1999 & 104 & 41 & 198 \\
2000 & 105 & 38 & 209
\end{tabular}




$\begin{array}{lrrl}2001 & 102 & 40 & 207 \\ 2002 & 102 & 41 & 218 \\ 2003 & 102 & 36 & 205 \\ 2004 & 99 & 41 & 212 \\ 2005 & 99 & 43 & 217 \\ 2006 & 95 & 49 & 214 \\ 2007 & 95 & 44 & 207 \\ 2008 & 101 & 39 & 210 \\ 2009 & 98 & 42 & 198 \\ 2010 & 95 & 49 & 187 \\ 2011 & 93 & 52 & 185 \\ 2012 & 91 & 60 & 180\end{array}$

Table S2a: Geographic Covariate types

Data Category

Distance to Airports

Distance to Coastline

Distance to Railroads

Distance to Railyards

Roads

Intersections

Population

Land use 2006

Land use 1990s

Distance to Ports

Truck Routes

Impervious Surface

Elevation
Source

NEI Database

TeleAtlas

TeleAtlas

US Census Bureau

2006 MRLC

USGS

National Geospatial Intelligence Agency

Bureau of Transportation Statistics

National Landcover Dataset

National Elevation Dataset
Buffer size

$50 \mathrm{~m}, 100 \mathrm{~m}, 150 \mathrm{~m}$, $300 \mathrm{~m}, 400 \mathrm{~m}, 500 \mathrm{~m}$, $750 \mathrm{~m}, 1 \mathrm{~km}, 1.5 \mathrm{~km}$, $3 \mathrm{~km}, 5 \mathrm{~km}$ $500 \mathrm{~m}, 1 \mathrm{~km}, 3 \mathrm{~km}$ $500 \mathrm{~m}, 1 \mathrm{~km}, 2 \mathrm{~km}$, $2.5 \mathrm{~km}, 3 \mathrm{~km}, 5 \mathrm{~km}$, $10 \mathrm{~km}, 15 \mathrm{~km}$ $50 \mathrm{~m}, 100 \mathrm{~m}, 150 \mathrm{~m}$, $300 \mathrm{~m}, 400 \mathrm{~m}, 500 \mathrm{~m}$, $750 \mathrm{~m}, 1 \mathrm{~km}, 1.5 \mathrm{kmg}$, $3 \mathrm{~km}, 5 \mathrm{~km}$ $50 \mathrm{~m}, 100 \mathrm{~m}, 150 \mathrm{~m}$, $300 \mathrm{~m}, 400 \mathrm{~m}, 500 \mathrm{~m}$ $750 \mathrm{~m}, 1 \mathrm{~km}, 1.5 \mathrm{kmg}$, $3 \mathrm{~km}, 5 \mathrm{~km}, 10 \mathrm{~km}$, $15 \mathrm{~km}$

$50 \mathrm{~m}, 100 \mathrm{~m}, 150 \mathrm{~m}$, $300 \mathrm{~m}, 400 \mathrm{~m}, 500 \mathrm{~m}$, $750 \mathrm{~m}, 1 \mathrm{~km}, 3 \mathrm{~km}, 5 \mathrm{~km}$ $1 \mathrm{~km}, 5 \mathrm{~km}$ 
$250 \mathrm{~m}, 500 \mathrm{~m}, 1 \mathrm{~km}$, $2.5 \mathrm{~km}, 5 \mathrm{~km}, 7.5 \mathrm{~km}$, NDVI*

Table S2b: Land-use categories (2006)

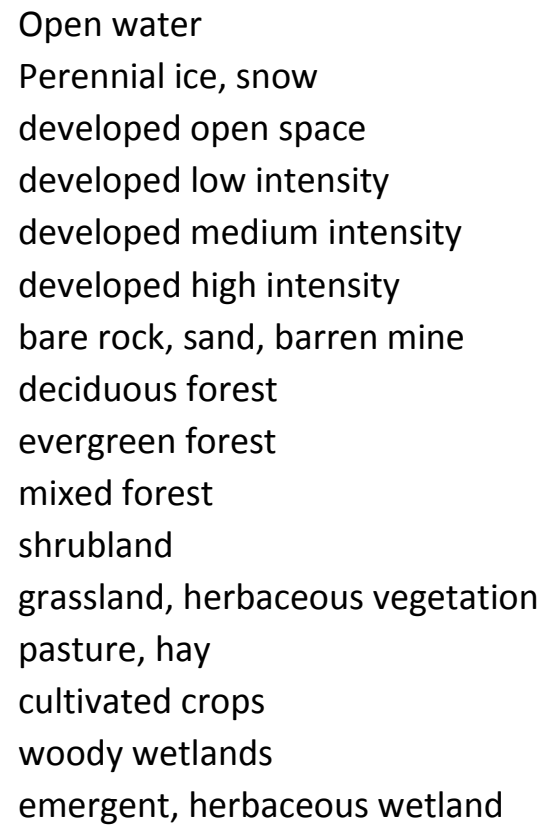

Table S3: Distance between a test-set monitor and its nearest training-set neighbor

$\begin{array}{crrrrr}\text { Cross-validation } & \text { Year } & \text { Minimum } & \text { Maximum } & \text { Mean } & \text { Median } \\ \text { conventional } & 1990 & 0.3 & 589 & 40 & 15 \\ & 2006 & 1.5 & 968 & 42 & 22 \\ \text { cluster } & 1990 & 16.4 & 1158 & 258 & 224 \\ & 2006 & 33.2 & 1251 & 265 & 220\end{array}$

Table S4: Regression Coefficients for the Universal Kriging model in 1990 and 2006

\begin{tabular}{clrrc} 
Year & Variable & West Coast & West & East \\
1990 & Intercept & 3.137 & 3.047 & 2.678 \\
& PLS1 & 0.082 & 0.107 & 0.08 \\
& PLS2 & 0.047 & 0.057 & 0.029 \\
\multirow{2}{*}{2006} & Satellite NO2 & 0.826 & 1.619 & 0.787 \\
& Intercept & 2.734 & 1.836 & 2.126 \\
& PLS1 & 0.058 & 0.09 & 0.069
\end{tabular}



PLS2
0.052
0.024
0.031
Satellite NO2
0.55
1.613
0.632

Regression coefficients (beta estimates) for the universal kriging model with satellite data in years 1990 and 2006. This table demonstrates that the modeling parameters are estimate separately for each year. Note that PLS components are defined differently in each year (see Figure S1). Regression coefficients for non-kriging (land-use regression only) are not shown, but similarly vary within region and from year to year.

Table S5: Kriging Parameters by year

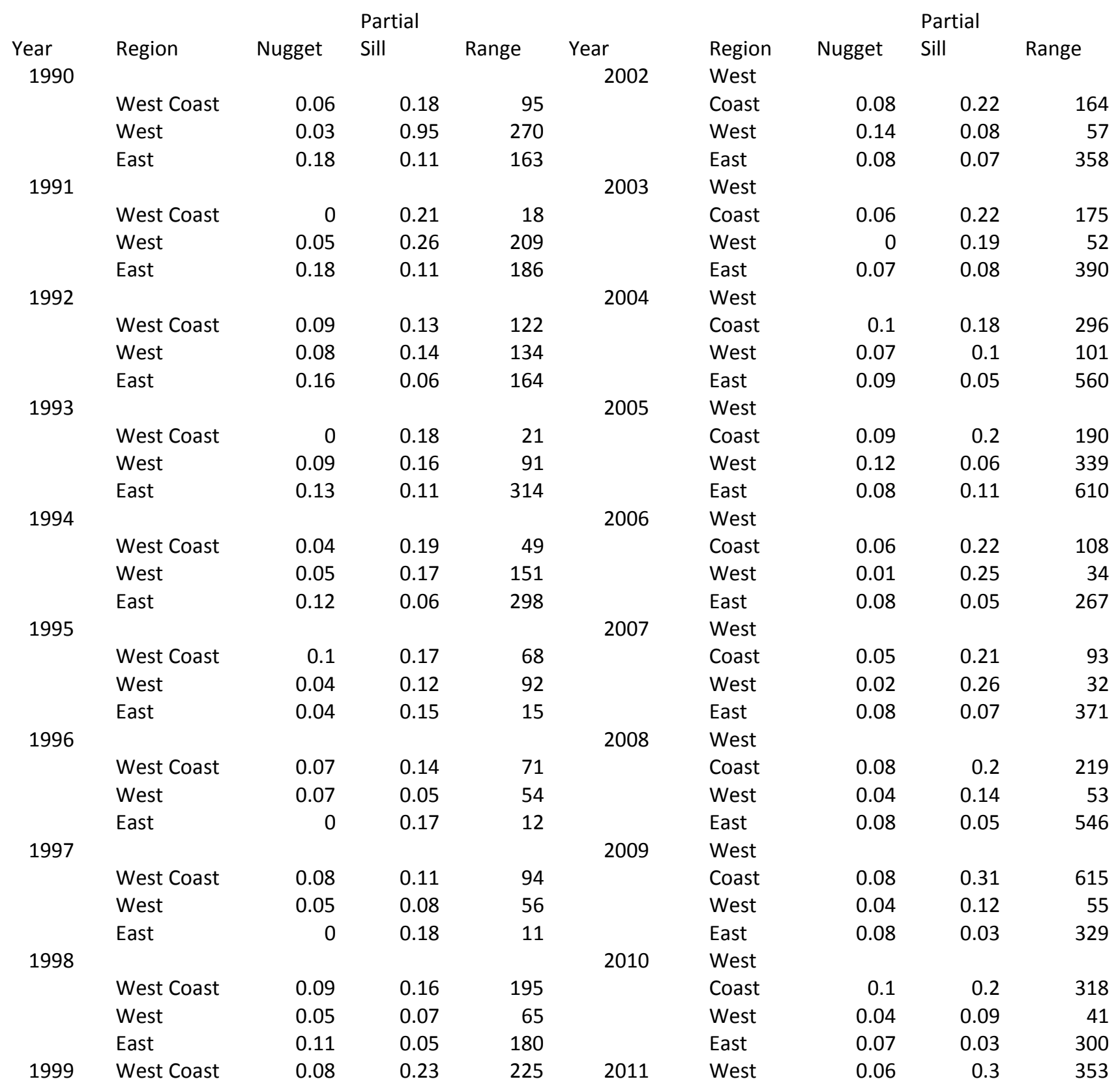




\begin{tabular}{|c|c|c|c|c|c|c|c|c|c|}
\hline & & & & & & Coast & & & \\
\hline & West & 0.09 & 0.05 & 126 & & West & 0.04 & 0.07 & 43 \\
\hline & East & 0.1 & 0.05 & 209 & & East & 0.07 & 0.03 & 327 \\
\hline \multirow[t]{4}{*}{2000} & & & & & 2012 & West & & & \\
\hline & West Coast & 0.06 & 0.24 & 147 & & Coast & 0.08 & 0.39 & 457 \\
\hline & West & 0.19 & 0.08 & 79 & & West & 0.12 & 0.01 & 3 \\
\hline & East & 0.07 & 0.06 & 243 & & East & 0.08 & 0.02 & 543 \\
\hline \multirow[t]{3}{*}{2001} & West Coast & 0.07 & 0.26 & 169 & & & & & \\
\hline & West & 0.09 & 0.04 & 170 & & & & & \\
\hline & East & 0.09 & 0.03 & 186 & & & & & \\
\hline
\end{tabular}

This table shows the estimates from the exponential variograms for the nugget (tau squaredmeasurement error or spatial discontinuity), the partial sill (sigma squared, variance at large distance), and the range (rho, distance at which spatial correlation decays) for each year. 